This Section of Epidemiology and Psychiatric Sciences appears in each issue of the Journal to stress the role of the epidemiological approach to promote advances in the field of clinical psychopharmacology, with a particular attention to controversial findings. The ultimate aims are to help develop a more critical attitude towards the results of research studies published in the international literature, to promote original research projects with higher methodological standards, and to implement the most relevant results of research in every-day clinical practice. These contributions are written in house by the journal's editorial team or commissioned by the Section Editor (no more than 1000 words, short unstructured abstract, 4 key-words, one Table or Figure and up to ten references).

Corrado Barbui, Section Editor

\title{
Access and use of psychotropic medicines in low- resource settings
}

\author{
C. Barbui* \\ Department of Public Health and Community Medicine, Section of Psychiatry, University of Verona, Verona, Italy
}

Improving access and rational use of essential medicines at all levels of care is a global challenge. Key issues related to the provision and rational use of psychotropic medicines have recently been analysed by Padmanathan et al. who conducted a survey of the psychotropic medicines management cycle in Bihar, the third most populous state of India with approximately 104 million people, of whom $88.7 \%$ live in rural areas. It was found that availability, distance and cost were the main barriers to access and utilisation. Travelling was reported to be particularly problematic because it is expensive and may also be unfeasible for service users who are acutely ill. In this commentary, the results of this survey are discussed in view of their global policy implications for low-resource settings.

Received 23 December 2014; Revised 7 February 2015; Accepted 12 February 2015; First published online 19 March 2015

Key words: Low- and middle-income countries, psychotropic medicines, rational use.

As the awareness of the importance of mental health increases, international organisations face the challenge of providing evidence-based guidance and good practices to assist countries in the provision of mental health care (Barbui et al. 2010; Collins et al. 2011; Dua et al. 2011; Tol et al. 2011, 2014). Recently the World Health Organization (WHO) and the Gulbenkian Mental Health Platform have collaborated to generate information to help meet this challenge, in the form of a series of thematic papers on pressing mental health issues of our time. One of these thematic papers emphasised that mental health systems should 'ensure the availability of essential medicines at all levels of the health system (and allow trained,

* Address for correspondence: Professor C. Barbui, Department of Public Health and Community Medicine, Section of Psychiatry, University of Verona, Piazzale L.A. Scuro, 10 - 37134 Verona, Italy.

(Email: corrado.barbui@univr.it) non-specialist providers to prescribe them)'. This concept refers to the issue of improving access to a selected range of psychotropic medicines, and implementing rational prescribing policies (World Health Organization and Calouste Gulbenkian Foundation, 2014).

Key issues related to the provision and rational use of psychotropic medicines have recently been analysed by Padmanathan et al. who conducted a critical analysis of the psychotropic medicines management cycle (selection, procurement, distribution and use) in Bihar, the third most populous state of India with approximately 104 million people, of whom $88.7 \%$ live in rural areas (Padmanathan et al. 2014). In Bihar the mental health system includes three main settings: government hospitals, Non-Governmental Organization (NGO) camps and private psychiatrists. Padmanathan et al. reported that if government services are unavailable, patients are referred to mental health camps. One 
psychiatrist is present at each camp, and psychotropic medicines are provided for free. Service users are then followed up in their own locality by one of 14 local partner NGOs. Alternatively, private psychiatrists may be consulted. At this step the main barriers identified were: lack of regular availability of psychotropic medicines in some governmental facilities, difficulties paying for the medicines when these were available through private pharmacies only and distance, as several service users reported spending over an hour travelling to access treatment, with a minority spending over $5 \mathrm{~h}$ travelling. Travelling was reported to be particularly problematic because it is expensive, it requires several free hours and may also be unfeasible for service users who are acutely ill. Clearly, these barriers may have a relevant impact on the provision of psychotropic medicines and, when medicines are prescribed, may lead to irregular use and poor adherence in the longterm. On this specific issue Padmanathan et al. noted that the pragmatic approach of providing large quantities of medicines to last several months, and undertaking psychiatric consultations without the service user being present, were associated with serious safety concerns.

In terms of medicine selection strategy, Bihar produces a customised state level Essential Drugs List, to be used as a guideline for clinical practice and an indicator of medication availability at government facilities. The list is updated at least every 2 years by a core committee of experts and government officials, using similar criteria to those used by WHO when updating the WHO list of essential medicines (Purgato \& Barbui, 2012; Barbui \& Purgato, 2014). As an example, for antipsychotic medicines the Bihar Essential Drugs List includes haloperidol and trifluoperazine, albeit the National List of Essential Medicines of India 2011 also contains olanzapine and chlorpromazine. At the state mental health hospital, however, in addition to olanzapine, risperidone was also available. Padmanathan et al. noted that the reasons for these differences between different settings were unclear. Psychiatrists working at the camps may also issue requests of psychotropic medicines, based on the Bihar's Essential Drugs List.

The current government medicines procurement and management system was reported to be well organised, with a recently implemented centralised procurement system with the potential to bring about significant improvements. In addition, the mandatory testing of stock is beneficial in ensuring quality is upheld (Padmanathan et al. 2014).

In terms of medicine use in Bihar, it is striking to note that antipsychotics, typically used for severe mental disorders, were more commonly prescribed than antidepressants, which are indicated for depressive and anxiety disorders and, more generally, for common mental disorders. Among antipsychotics, it is surprising to note that the use of olanzapine was far more than other antipsychotics used in mental health camps, even much more than risperidone, another second generation medication which is included in the WHO essential medicines list. This raises an issue of longterm safety, as the problematic adverse effects of these newer antipsychotics, including metabolic syndromes, can pose a great challenge for patients and clinicians. According to Padmanathan et al. this pattern of use may suggests that individuals with common mental disorders do not receive pharmacological treatment, but may also reflect the habit of prescribing antipsychotics as sleeping pills.

This qualitative/quantitative survey of issues related to access and use of psychotropic medicines is of paramount relevance, as it is brightly emphasised, with a practical example, that a large treatment gap between what we know and what we do is still a major challenge in mental health care. This is true in Bihar as well as in many other low-resource settings over the world (Eaton, 2008; McBain et al. 2012; Jordans et al. 2013). Epidemiological data have consistently shown that only a minority of those suffering from mental disorders receive basic evidence-based treatments, and relatively few people with mental disorders consult a physician (Tol et al. 2013). In developing countries, health systems often are not able to provide even the most essential mental care, including essential medicines for mental disorders (White et al. 2014). Strategies aimed at improving access and rational use of psychotropic medicines should therefore receive more attention, with particular emphasis on the following topics (World Health Organization, 2005):

(1) Rational selection of medicines: national and/or international medicines agencies should develop rules to identify a selected number of psychotropic medicines to be included into national/state/local formularies on the basis of efficacy, safety, comparative efficacy, cost-effectiveness, feasibility and other issues (Barbui \& Bighelli, 2013). The WHO list of essential medicines may be used as a reference guide.

(2) Rational access to medicines: for each medicine selected for inclusion, policy considerations should be formulated on acquisition cost and coverage (whether the acquisition cost is covered, in full or part, by the health system or by public or private or other insurance schemes, or whether individuals pay the full price), prescription restrictions (whether a prescription is required to get the medicine, who is allowed to issue the first and subsequent prescriptions, settings where prescriptions can be issued, 
whether prescriptions have other restrictions, for example in terms of diagnosis or laboratory requirements or others).

(3) Functioning health care system: medicines should be a part of the mental health system which guarantees regular procurement and distribution of medicines, in order to assure availability and sustainability in the long-term (Eaton, 2008; McBain et al. 2012; Jordans et al. 2013); evidence-based treatment recommendations should be available in order to put new medicines in the wider context of mental health care; epidemiological monitoring facilities should be developed in order to monitor prescribing trends at a country or province or district level.

(4) Assessment: process and outcome indicators should be developed to regularly monitor the degree of coherence between recommendations and current clinical practice.

(5) Integration and interaction: policy considerations should be formulated on how the use of medicines may be integrated with the provision of psychological and psychosocial interventions, and how health care providers, pharmacists, consumers, families and other locally relevant stakeholders should interact to optimise the prescribing process.

(6) Education: unbiased information on benefits and harms associated with the use of psychotropic medicines should be regularly provided, not only with training activities but also by increasing access and critical use of unbiased scientific databases.

(7) Research: policy considerations should be formulated on the development of local, national or international basic research infrastructures aimed at conducting pragmatic and independent projects oriented to increase the rational use of psychotropic medicines.

\section{Acknowledgements}

None.

\section{Financial support}

No financial support was received for this paper from any funding agency, commercial or not-for-profit sectors

\section{Statement of interest}

None.

\section{References}

Barbui C, Bighelli I (2013). A new approach to psychiatric drug approval in Europe. PLoS Medicine 10, e1001530.

Barbui C, Purgato M (2014). Decisions on WHO's essential medicines need more scrutiny. BMJ 349, g4798.
Barbui C, Dua T, van Ommeren M, Yasamy M, Fleischmann A, Clark N, Thornicroft G, Hill S, Saxena S (2010). Challenges in developing evidence-based recommendations using the GRADE approach: the case of mental, neurological, and substance use disorders. Plos Medicine 7, e1000322.

Collins PY, Patel V, Joestl SS, March D, Insel TR, Daar AS, Anderson W, Dhansay MA, Phillips A, Shurin S, Walport M, Ewart W, Savill SJ, Bordin IA, Costello EJ, Durkin M, Fairburn C, Glass RI, Hall W, Huang Y, Hyman SE, Jamison K, Kaaya S, Kapur S, Kleinman A, Ogunniyi A, Otero-Ojeda A, Poo MM, Ravindranath V, Sahakian BJ, Saxena S, Singer PA, Stein DJ (2011). Grand challenges in global mental health. Nature 475, 27-30.

Dua T, Barbui C, Clark N, Fleischmann A, Poznyak V, van Ommeren M, Yasamy MT, Ayuso-Mateos JL, Birbeck GL, Drummond C, Freeman M, Giannakopoulos P, Levav I, Obot IS, Omigbodun O, Patel V, Phillips M, Prince M, Rahimi-Movaghar A, Rahman A, Sander JW, Saunders JB, Servili C, Rangaswamy T, Unutzer J, Ventevogel P, Vijayakumar L, Thornicroft G, Saxena S (2011).

Evidence-based guidelines for mental, neurological, and substance use disorders in low- and middle-income countries: summary of WHO recommendations. PLoS Medicine 8, e1001122.

Eaton J (2008). Ensuring access to psychotropic medication in sub-Saharan Africa. African Journal of Psychiatry 11, 179-181.

Jordans MJ, Luitel NP, Tomlinson M, Komproe IH (2013). Setting priorities for mental health care in Nepal: a formative study. BMC Psychiatry 13, 332.

McBain R, Norton DJ, Morris J, Yasamy MT, Betancourt TS (2012). The role of health systems factors in facilitating access to psychotropic medicines: a cross-sectional analysis of the WHO-AIMS in 63 low- and middle-income countries. PLoS Medicine 9, e1001166.

Padmanathan P, Singh M, Mannarath SC, Omar M, Raja S (2014). A rapid appraisal of access to and utilisation of psychotropic medicines in Bihar, India. International Journal of Mental Health Systems 8, 29.

Purgato M, Barbui C (2012). What is the WHO essential medicines list? Epidemiology and Psychiatric Sciences 21, 343-345.

Tol WA, Barbui C, Galappatti A, Silove D, Betancourt TS, Souza R, Golaz A, van Ommeren M (2011). Mental health and psychosocial support in humanitarian settings: linking practice and research. Lancet 378, 1581-1591.

Tol WA, Rees SG, Silove DM (2013). Broadening the scope of epidemiology in conflict-affected settings: opportunities for mental health prevention and promotion. Epidemiology and Psychiatric Sciences 22, 197-203.

Tol WA, Barbui C, Bisson J, Cohen J, Hijazi Z, Jones L, de Jong JT, Magrini N, Omigbodun O, Seedat S, Silove D, Souza R, Sumathipala A, Vijayakumar L, Weissbecker I, Zatzick D, van Ommeren M (2014). World health organization guidelines for management of acute stress, PTSD, and bereavement: key challenges on the road ahead. PLoS Medicine 11, e1001769.

White J, Pearce J, Morrison S, Dunstan F, Bisson JI, Fone DL (2014). Risk of post-traumatic stress disorder following 
traumatic events in a community sample. Epidemiology and Psychiatric Sciences Mar 17, 1-9.

World Health Organization (2005). Improving Access and use of Psychotropic Medicines. World Health Organization: Geneva.
World Health Organization and Calouste Gulbenkian Foundation (2014). Integrating the Response to Mental Disorders and other Chronic Diseases in Health Care Systems. World Health Organization: Geneva. 